\title{
Values of miR-34a and miR-218 expression in the diagnosis of cervical cancer and the prediction of prognosis
}

\author{
PING WANG ${ }^{1 *}$, GUANYUN ZHAI $^{2 *}$ and YUNYAN BAI ${ }^{3}$ \\ ${ }^{1}$ Department of Obstetrics and Gynecology, Dezhou People's Hospital; ${ }^{2}$ Department of Laboratory Medicine, \\ The Maternity and Child Health Family Planning Service Center of Decheng District; \\ ${ }^{3}$ Department of Laboratory Medicine, Dezhou People's Hospital, Dezhou, Shandong 253000, P.R. China
}

Received August 21, 2017; Accepted December 12, 2017

DOI: $10.3892 / \mathrm{ol} .2018 .7791$

\begin{abstract}
The expression levels of microribonucleic acid 34a (miR-34a) and miR-218 in the serum and tumor tissues of patients with cervical cancer were investigated to explore their relationship with the diagnosis of cervical cancer. Fifty patients with cervical cancer were selected, and 30 normal patients were selected as the control group. The expression levels of miR-34a and miR-218 were detected by quantitative real-time polymerase chain reaction. The relationship between the expression of miR-34a and miR-218 was analyzed using Pearson's correlation coefficient, and the receiver operating characteristic (ROC) curve was plotted for the analysis of values of the expression of miR-34a and miR-218. The correlation of the expressions of miR-34a and miR-218 in the serum with pathological parameters and the prognosis was analyzed. The expression levels of miR-34a and miR-218 in cervical cancer patients were significantly lower than those in normal patients. The ROC curve showed the area under curve (AUC) of miR-34a was 0.893, and miR-218 was 0.794 . The low expression of miR-34a in patients with cervical cancer was correlated with the degree of tumor differentiation, lymph node metastasis and the International Federation of Gynecology and Obstetrics staging. The low expression of miR-218 was related to the degree of differentiation as well as invasion and metastasis. The 5-year overall survival rate of patients was $66 \%$, and the low expression of miR-34a and miR-218 indicated a worse survival prognosis. The low expression of miR-34a in patients with cervical cancer is related to the degree of tumor differentiation as well as invasion and metastasis, and the low expression of miR-218 is related to
\end{abstract}

Correspondence to: Dr Yunyan Bai, Department of Laboratory Medicine, Dezhou People's Hospital, 1751 Xinhu Street, Dezhou, Shandong 253000, P.R. China

E-mail: shd030303@163.com

${ }^{*}$ Contributed equally

Key words: miR-34a, miR-218, diagnosis, prognosis, cervical cancer the degree of tumor differentiation, invasion and metastasis and clinical staging. miR-34a and miR-218 in the serum can be used as markers for the diagnosis of cervical cancer and reference indicators for the evaluation of prognosis.

\section{Introduction}

Cervical cancer is one of the common malignant tumors in females, which seriously threatens their health and life. Its incidence rate is second only to breast cancer among malignant tumors in females. There are about 500,000 new cases each year around the world, in which 267,000 new cases occur in Asia annually (1). In recent years, cervical cancer has frequently occured in young people. Cervical cancer is prone to invasion and metastasis in patients, thus leading to poor prognosis of patients with cervical cancer, and the 5-year survival rate is only about from 30 to $60 \%$ (2).

Micro-ribonucleic acid (miRNA) is a non-coding small RNA molecule with a length of about 22 nucleotides and can be specifically paired with the three prime untranslated region (3'-UTR) of the target gene, thus leading to degradation of the target gene messenger RNA (mRNA) or inhibiting the translation process so as to affect the expression of target genes (3). In 1993, Lee et al found miRNAs in Caenorhabditis elegans for the first time, and discovered that miRNAs play key roles in cell development, differentiation, proliferation and apoptosis (4). At the same time, it was found that miRNAs are abnormally expressed in many kinds of tumors and are closely related to the occurrence and development of tumors (5).

Previously, a study showed that miR-34a is an important target for tumor suppressor protein p53 (6). miR-34a can specifically bind to mRNAs of cyclin E2, cyclin-dependent kinase 4, c-Myc, and B-cell lymphoma 2 at 3'-UTR, which leads to mRNA degradation of these proteins, thus blocking cell cycle, inhibiting cell proliferation and promoting tumor cell apoptosis $(7,8)$. The miR-218 gene is located on chromosome $5 \mathrm{q} 16$ and is downregulated in tissues and cells of tumors such as gastric cancer, head and neck squamous cell carcinoma and breast cancer. A study revealed that the miR-218 gene is associated with tumor growth, invasion and metastasis (9). In addition, it has been found that miR-218 expression is downregulated in cervical cancer cell lines and cervical cancer, and it is speculated that the expression of 
miR-218 is closely related to the occurrence and development of cervical cancer (10).

A study showed that miRNAs are differently expressed in different tumor tissues at different development stages of the tumors (11). In addition, miRNAs circulating in human serum or plasma are of great importance for early diagnosis, staging and prognosis of tumors (12). Therefore, we are committed to the study on the expression of miRNAs in the serum of patients with cervical cancer, and confirm its possible effectiveness in the early diagnosis and prognosis evaluation of cervical cancer. The relationship between the expression of miR-34a and miR-218 in peripheral blood of patients with cervical cancer and those in tumor tissues and the correlation of the expression of miR-34a and miR-218 with pathological parameters and the prognosis of cervical cancer are rarely reported in the literature. Therefore, this study preliminarily investigated the values of miR-34a and miR-218 in the diagnosis of cervical cancer and the correlation of their expression with clinicopathological parameters and the prognosis of patients by detecting the expression levels of miR-34a and miR-218 in the serum and tumor tissues of patients with cervical cancer in combination with the clinical data of patients.

\section{Materials and methods}

Materials. A total of 50 patients with cervical cancer admitted to Dezhou People's Hospital from January, 2010 to December, 2016 were collected. They were aged 52.3 \pm 12.7 years, and none received preoperative chemotherapy, radiotherapy or endocrine therapy. Tissue specimens were pathologically diagnosed with cervical cancer. A total of 30 patients with uterine fibroids receiving uterine total resection who were admitted at the same period were selected as the control group. They were aged $49.6 \pm 13.2$ years, and their tissue specimens were histopathologically confirmed with normal cervical tissues. Materials were drawn from tissue specimens in the operation within $30 \mathrm{~min}$ and then immediately placed in liquid nitrogen for preservation. Peripheral venous blood $(5 \mathrm{ml})$ was collected before operation as peripheral blood samples. After standing at room temperature for $30 \mathrm{~min}$, the samples were centrifuged at $10 \mathrm{~min}$ at $2,860 \mathrm{x} \mathrm{g}$, and the supernatant was separated and placed in at $-80^{\circ} \mathrm{C}$. The present study was approved by the Clinical Ethics Committee, and all the patients or family members signed the informed consent; TRIzol kit (Invitrogen; Thermo Fisher Scientific, Inc., Waltham, MA, USA); primer synthesis, reverse transcription kits and quantitative real-time polymerase chain reaction (qRT-PCR) kits (all from Takara Biotechnology Co., Ltd., Dalian, China).

Detection of the expression of $\mathrm{miR}-34 \mathrm{a}$ and $\mathrm{miR}-218$ in tissue specimens and serum of patients by $q R T-P C R$. A total of $100 \mathrm{mg}$ frozen tissues and $50 \mu \mathrm{l}$ serum of patients were selected, respectively. The total RNA was extracted according to the instructions of TRIzol kit. The ratio of A260/A280 was measured using a spectrophotometer (Hitachi, Ltd., Tokyo, Japan). The ratio of A260/A280 (1.8-2.0) could be used for subsequent tests. Total RNA sample $(1 \mu \mathrm{g})$ was extracted from patients in the two groups, respectively, and complementary deoxyribonucleic acid (cDNA) was obtained through reverse transcription according to the instructions of reverse
Table I. Primer sequences of qRT-PCR.

\begin{tabular}{ll}
\hline Gene & \multicolumn{1}{c}{ Primer sequence } \\
\hline miR-34a & F: 5'-CGGTATCATTTGGCAGTG-3' \\
& R: 5'-GTGCAGGGTCCGAGGT-3' \\
miR-34a8 & F: 5'-GGAGTGGCGAATGGTAGTGGAGT-3' \\
& R: 5'-ACCAGGCTGGACAGTAGAGCG-3' \\
U6 & F: 5'-GCTTCGGCAGCACATATACTAAAAT-3' \\
& R: 5'-C-CGCTTCACGAATTTGCGTGTCAT-3'
\end{tabular}

qRT-PCR, quantitative real-time polymerase chain reaction.

transcription kits. Reaction conditions: At $16^{\circ} \mathrm{C}$ for $30 \mathrm{~min}$, at $42^{\circ} \mathrm{C}$ for $30 \mathrm{~min}$ and at $75^{\circ} \mathrm{C}$ for $15 \mathrm{~min}$. After that, with cDNA as a template and U6 RNA as the control gene, the expression levels of miR-218 and miR-34a were detected according to the instructions of qRT-PCR kits. RT-PCR amplification conditions: At $95^{\circ} \mathrm{C}$ for $5 \mathrm{~min}$, at $95^{\circ} \mathrm{C}$ for $15 \mathrm{sec}$, at $60^{\circ} \mathrm{C}$ for $30 \mathrm{sec}$, and at $68^{\circ} \mathrm{C}$ for $30 \mathrm{sec} ; 30$ cycles. In all reactions, three wells for repeated use were set up. The primer sequences of miR-34a, miR-218 and U6 are shown in Table $\mathrm{I}_{\text {. }} \mathrm{C}_{\mathrm{q}}$ values were from the instrument software, and the relative expression of the target gene was expressed as $2^{-\Delta \mathrm{Cq}}$.

The correlation of the expression of $\mathrm{miR}-34 \mathrm{a}$ and $\mathrm{miR}-218 \mathrm{in}$ the serum of patients. According to the expression levels of miR-34a and miR-218 in the serum of patients with cervical cancer, the patients with cervical cancer were divided into: i) miR-34a high expression group ( $\geq 2.54)$; ii) miR-34a low expression group $(<2.54)$; iii) miR-218 high expression group ( $\geq 2.63)$; iv) and miR-218 low expression group $(<2.63)$ with the average expression level as the standard. The correlation of the expression of miR-34a and miR-218 with pathological parameters and the prognosis of patients was analyzed according to the clinicopathological data.

Statistical analysis. Data were analyzed using SPSS 18.0 software (SPSS, Inc., Chicago, IL, USA). Measurement data were detected using the t-test. Intergroup comparisons of count data were conducted using the $\chi^{2}$ test. The correlation analysis was performed by Pearson's correlation coefficient, and the receiver operator characteristic (ROC) curve was plotted. $\mathrm{P}<0.05$ was considered to indicate a statistically significant difference.

\section{Results}

The expression of miR-34a and miR-218 in tissue specimens of patients. qRT-PCR results are shown in Fig. 1. The expression level of miR-34a in cervical cancer tissues was significantly lower than that in normal cervical tissues, and the difference was statistically significant $(\mathrm{P}<0.01)$. The expression level of miR-218 in cervical cancer tissues was significantly lower than that in normal cervical tissues, and the difference was statistically significant $(\mathrm{P}<0.01)$.

Detection of the expression of $\mathrm{miR}-34 \mathrm{a}$ and $\mathrm{miR}-218$ in the serum of patients by $q R T-P C R$. As shown in Fig. 2, compared 
A

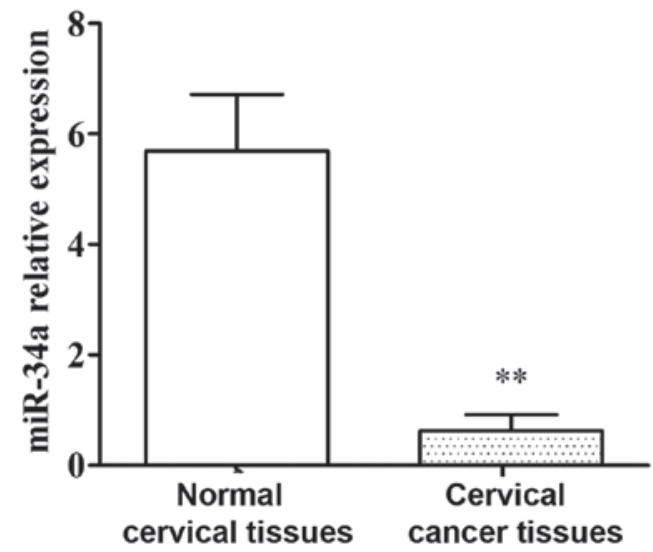

B

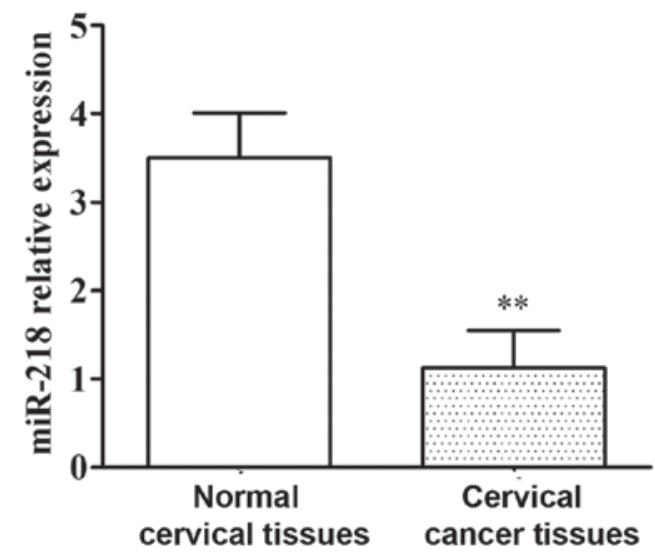

Figure 1. Detection of the expression of miR-218 and miR-34a in tissue specimens by qRT-PCR. Compared with those in normal cervical tissues, the expression levels of miR-34a and miR-218 in cervical cancer tissues are significantly decreased, ${ }^{* *} \mathrm{P}<0.01$. (A) The expression of miR-34a in tissues. (B) The expression of miR-218 in tissues. qRT-PCR, quantitative real-time polymerase chain reaction.

A

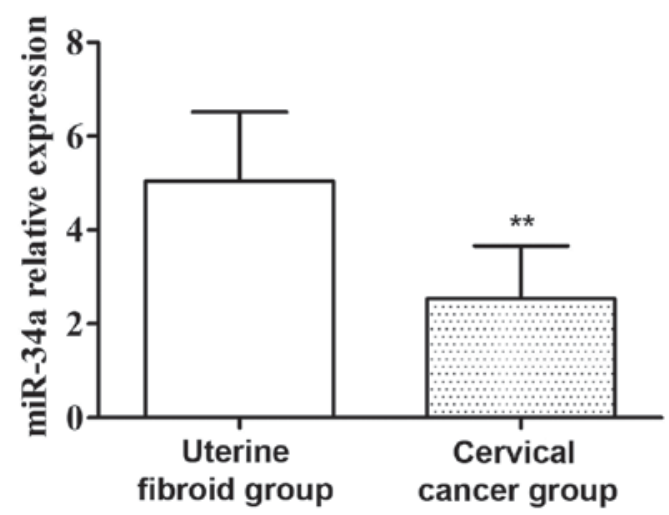

B

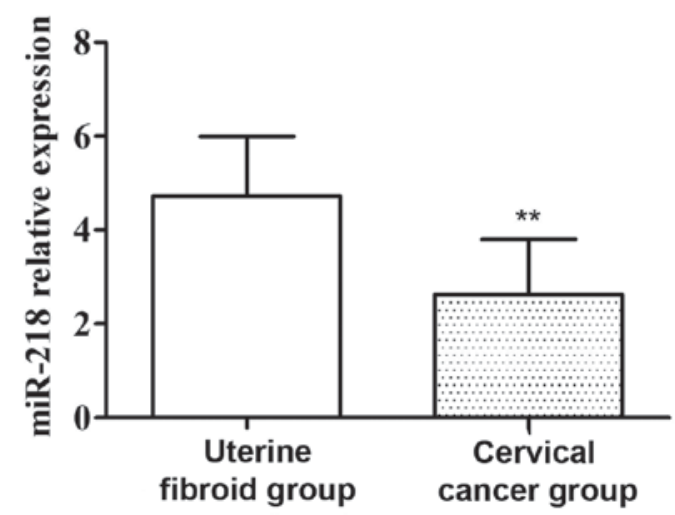

Figure 2. Detection of the expression of miR-34a and miR-218 in the serum of patients by qRT-PCR. Compared with patients in the uterine fibroid group, the expression levels of miR-34a and miR-218 in the serum of patients with cervical cancer are significantly decreased, ${ }^{* *} \mathrm{P}<0.01$. (A) The expression of miR-34a in the serum. (B) The expression of miR-218 in the serum.

with those of patients in the uterine fibroid group, the expression levels of miR-34a and miR-218 in the serum of patients with cervical cancer were significantly decreased, and the differences were statistically significant $(\mathrm{P}<0.01)$.

The correlation between the expression of miR-34a and miR-218 in the serum and those in the tumor tissues of patients with cervical cancer. Pearson's correlation coefficient was used to analyze the correlation between the expression of miR-34a and miR-218 in the serum and those in tumor tissues of patients. As shown in Table II, the expression levels of miR-34a and miR-218 in the serum were positively correlated with those in tumor tissues of patients with cervical cancer $(\mathrm{P}<0.01)$.

Values of the expression of miR-34a and miR-218 in the serum of patients with cervical cancer in the diagnosis of cervical cancer. The ROC curve was plotted according to the relative expression levels of miR-34a and miR-218, and the area under curve (AUC) $0.893 \pm 0.035$ and $95 \%$ confidence interval (0.824-0.961) of miR-34a for the diagnosis of cervical cancer were calculated, and the diagnosis was relatively more
Table II. The correlation between the expression of miR-34a and miR-218 in the serum and those in the tumor tissues of patients with cervical cancer.

\begin{tabular}{lccc}
\hline Serum & Tumor tissues & $\mathrm{r}$ & P-values \\
\hline miR-34a & miR-34a & 0.697 & $<0.01$ \\
miR-218 & miR-218 & 0.758 & $<0.01$ \\
\hline
\end{tabular}

accurate. The AUC $0.794 \pm 0.050$ and $95 \%$ confidence interval (0.696-0.892) of miR-218 for the diagnosis of cervical cancer were calculated, and the diagnosis was relatively more accurate (Fig. 3).

The correlation of the expression of $\mathrm{miR}-34 \mathrm{a}$ and $\mathrm{miR}-218$ in the serum of patients with cervical cancer with clinical pathology. Statistics showed that there were 36 with low expression miR-34a (72.00\%) and 31 with low expression miR-218 $(62.00 \%)$ out of 50 patients with cervical cancer. The 
Table III. The correlation of the expression of miR-34a and miR-218 with the clinicopathological parameters of cervical cancer.

\begin{tabular}{|c|c|c|c|c|c|c|c|}
\hline \multirow{2}{*}{$\begin{array}{l}\text { Clinicopathological } \\
\text { parameters }\end{array}$} & \multirow[b]{2}{*}{ Case $(n)$} & \multicolumn{3}{|c|}{ miR-34a } & \multicolumn{3}{|c|}{$\operatorname{miR}-218$} \\
\hline & & Low expression & $\chi^{2}$ value & P-value & Low expression & $\chi^{2}$ value & P-value \\
\hline \multicolumn{8}{|l|}{ Age (years) } \\
\hline$\geq 40$ & 32 & 24 & 0.40 & $>0.05$ & 21 & 0.50 & $>0.05$ \\
\hline$<40$ & 18 & 12 & & & 10 & & \\
\hline \multicolumn{8}{|l|}{$\begin{array}{l}\text { Diameter of } \\
\text { tumor }\end{array}$} \\
\hline$\geq 4 \mathrm{~cm}$ & 28 & 22 & 1.36 & $>0.05$ & 17 & 0.04 & $>0.05$ \\
\hline$<4 \mathrm{~cm}$ & 22 & 14 & & & 14 & & \\
\hline \multicolumn{8}{|l|}{$\begin{array}{l}\text { Degree of tumor } \\
\text { differentiation }\end{array}$} \\
\hline Low differentiation & 21 & 9 & 15.25 & $<0.01$ & 8 & 8.78 & $<0.01$ \\
\hline Medium/high differentiation & 29 & 27 & & & 23 & & \\
\hline \multicolumn{8}{|l|}{ Lymph node metastasis } \\
\hline Yes & 35 & 30 & 5.14 & $<0.05$ & 26 & 7.74 & $<0.01$ \\
\hline No & 15 & 6 & & & 5 & & \\
\hline \multicolumn{8}{|l|}{ FIGO staging } \\
\hline I-II & 24 & 12 & 11.08 & $<0.01$ & 14 & 0.26 & $>0.05$ \\
\hline III-IV & 26 & 24 & & & 17 & & \\
\hline
\end{tabular}

FIGO, International Federation of Gynecology and Obstetrics.

correlation of the expression of miR-34a and miR-218 in the serum of patients with cervical cancer is shown in Table III. The $\chi^{2}$ test indicated that the low expression of miR-34a in the serum was correlated with the degree of tumor differentiation, invasion and metastasis and the International Federation of Gynecology and Obstetrics (FIGO) staging, and the low expression of miR-218 was associated with the degree of tumor differentiation as well as invasion and metastasis.

Analysis of the survival and prognosis of patients. Statistical analysis of the follow-up results of patients with cervical cancer showed that 33 patients survived and 17 died, and the 5-year overall survival rate was $66 \%$, in which the death of patients were caused by cervical cancer progress. Kaplan-Meier survival curve analysis showed that miR-34a high expression (Fig. 4A) and miR-218 low expression (Fig. 4B) had worse survival prognoses.

\section{Discussion}

In previous years, the incidence rate of cervical cancer has significantly increased in China, and the pathogenesis of cervical cancer is very complex, including the activation of proto-oncogene, anti-cancer abnormal expression, human papillomavirus infection and immune factors, as shown (13).

miRNAs play key roles in the occurrence and development of various malignant tumors, and it has been found that miRNAs are involved in the important processes, such as tumor cell proliferation, apoptosis, metabolism and differentiation $(14,15)$. miR-34a, a member of the miR-34 family, is commonly found in mammals and abnormally expressed in a variety of tumors, which can induce cell apoptosis, prevent cell invasion and block cell cycle progression (16-18). In recent years, the abnormal expression of miR-218 in tumor tissue has become a hot topic in tumor research. Studies have confirmed that the expression of miR-218 was downregulated in cervical cancer, gastric cancer and breast cancer, and miR-218 is closely related to the invasion and metastasis, differentiation and staging of tumors $(19,20)$.

In the serum of normal people, the expression of miRNAs has a good consistency and stability. When lesions occur in the body, the expression of miRNAs in the serum will also change correspondingly, so detecting the abnormally expressed miRNAs in the serum of cancer patients may become a simple, effective and fast tumor diagnosis method (21). Studies have confirmed that miR-34a and miR-218 have low expression in cervical cancer and are closely related to clinicopathological parameters and the prognosis of patients $(22,23)$.

In order to further investigate the expression of miR-34a and miR-218 in the serum and tumor tissues of patients with cervical cancer and their influence on the pathological parameters and prognosis of patients with cervical cancer, the expression levels of miR-34a and miR-218 in the serum and tumor tissues of patients with cervical cancer were detected using qRT-PCR in this study. The results revealed that compared with those in normal cervical tissues, the expression levels of miR-34a and miR-218 in cervical cancer tissues were significantly decreased, and the expression levels of miR-34a and miR-218 in the serum of patients with cervical cancer were significantly lower than those of patients with uterine fibroids. At the same time, Pearson's correlation coefficient showed that the expression of miR-34a and miR-218 in the serum were 
A

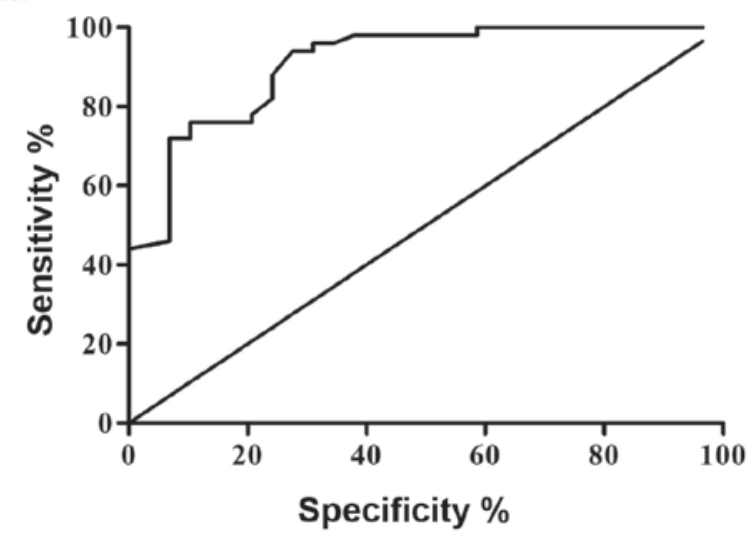

B

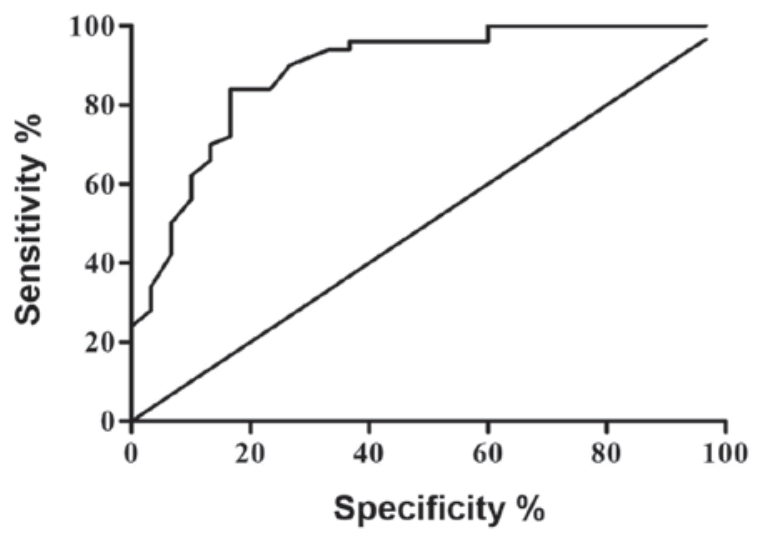

Figure 3. ROC curves of miR-34a and miR-218 in the diagnosis of cervical cancer. miR-34a and miR-218 have relatively better accuracy in the diagnosis of cervical cancer. (A) The ROC curve of miR-34a in the diagnosis of cervical cancer. (B) The ROC curve of miR-218 in the diagnosis of cervical cancer. ROC, receiver operating characteristic.

A

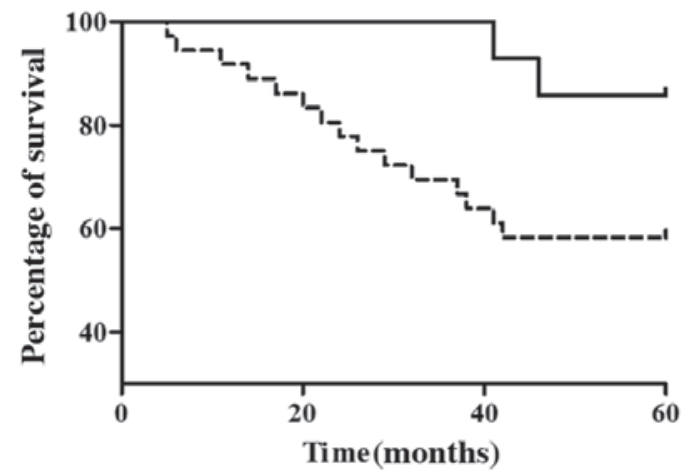

B
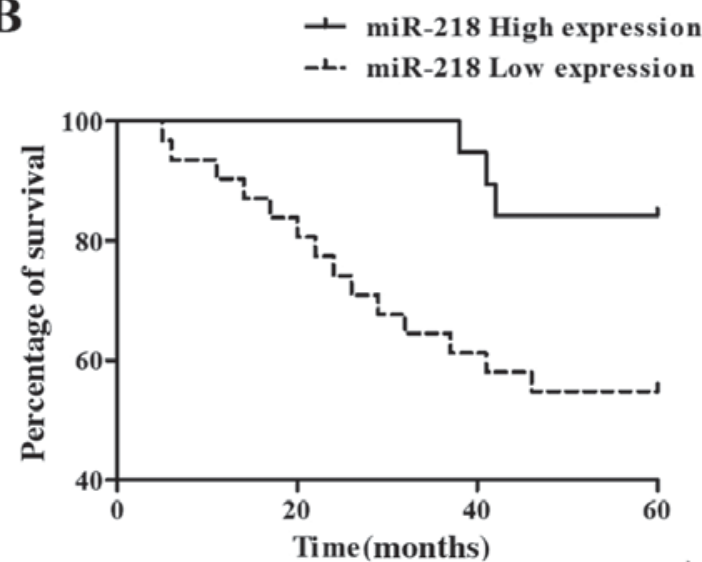

Figure 4. The Kaplan-Meier survival curve of the expression of miR-34a and miR-218 and cervical cancer. (A) Effects of the expression of miR-34a on the Kaplan-Meier survival curve of patients with cervical cancer. (B) Effects of the expression of miR-218 on the Kaplan-Meier survival curve of patients with cervical cancer.

positively correlated with those in cervical cancer tissues. The ROC curve analysis showed that the AUC of miR-34a was 0.893 and the $95 \%$ confidence interval was $0.824-0.961$; the AUC of miR-218 was 0.794 , and the $95 \%$ confidence interval was $0.696-0.892$, indicating that the diagnosis of cervical cancer using miR-34a and miR-218 is relatively more accurate. The correlation analysis of clinicopathological parameters of patients indicated that the low expression of miR-34a in the serum of patients with cervical cancer was correlated with the degree of tumor differentiation, lymph node metastasis and FIGO staging, and the low expression of miR-218 in the serum was related to the degree of differentiation as well as invasion and metastasis. The 5-year overall survival rate of patients was $66 \%(33 / 50)$, and the low expressions of miR-34a and miR-218 presented a worse survival prognosis.

In summary, the low expression of miR-34a and miR-218 are closely related to the occurrence and development of cervical cancer, especially to the degree of tumor differentiation as well as invasion and metastasis. Tumor detection by miRNAs in the serum of patients has many advantages. For example, it is minimally invasive, repeatable and simple and feasible. The study confirmed that miR-34a and miR-218 in the serum of patients with cervical cancer could be used as important reference indicators in the diagnosis and prognosis evaluation of cervical cancer.

\section{Competing interests}

The authors declare that they have no competing interests.

\section{References}

1. Jemal A, Bray F, Center MM, Ferlay J, Ward E and Forman D: J Torre LA: Global cancer statistics. CA Cancer J Clin 61: 69-90, 2011.

2. Hisamatsu T, Mabuchi S, Yoshino K, Fujita M, Enomoto T, Hamasaki T and Kimura T: Prediction of progression-free survival and response to paclitaxel plus carboplatin in patients with recurrent or advanced cervical cancer. Int $\mathrm{J}$ Gynecol Cancer 22: 623-629, 2012.

3. Zamore PD and Haley B: Ribo-gnome: The big world of small RNAs. Science 309: 1519-1524, 2005.

4. Lee RC, Feinbaum RL and Ambros V: The C.elegans heterochronic gene lin-4 encodes small RNAs with antisense complementarity to lin-14. Cell 75: 843-854, 1993. 
5. Garzon R, Calin GA and Croce CM: MicroRNAs in cancer Annu Rev Med 60: 167-179, 2009.

6. He X, He L and Hannon GJ: The guardian's little helper: microRNAs in the p53 tumor suppressor network. Cancer Res 67: 11099-11101, 2007.

7. Hermeking H: p53 enters the microRNA world. Cancer Cell 12: 414-418, 2007.

8. Bommer GT, Gerin I, Feng Y, Kaczorowski AJ, Kuick R, Love RE, Zhai Y, Giordano TJ, Qin ZS, Moore BB, et al: p53-mediated activation of miRNA34 candidate tumor-suppressor genes. Curr Biol 17: 1298-1307, 2007.

9. Kinoshita T, Hanazawa T, Nohata N, Kikkawa N, Enokida H, Yoshino $H$, Yamasaki $T$, Hidaka $H$, Nakagawa $M$, Okamoto Y, et al: Tumor suppressive microRNA-218 inhibits cancer cell migration and invasion through targeting laminin-332 in head and neck squamous cell carcinoma. Oncotarget 3 : 1386-1400, 2012.

10. Martinez I, Gardiner AS, Board KF, Monzon FA, Edwards RP and Khan SA: Human papillomavirus type 16 reduces the expression of microRNA-218 in cervical carcinoma cells. Oncogene 27: 2575-2582, 2008.

11. Võsa U, Vooder T, Kolde R, Vilo J, Metspalu A and Annilo T: Meta-analysis of microRNA expression in lung cancer. Int $\mathrm{J}$ Cancer 132: 2884-2893, 2012.

12. Schetter AJ, Okayama H and Harris CC: The role of microRNAs in colorectal cancer. Cancer J 18: 244-252, 2012.

13. Gu J, Li X, Liang Y, Qiao L, Ran D, Lu Y, Li X, Wei W and Zheng Q: Upregulation of URI/RMP gene expression in cervical cancer by high-throughput tissue microarray analysis. Int J Clin Exp Pathol 6: 669-677, 2013.

14. Fassan M, Croce CM and Rugge M: miRNAs in precancerous lesions of the gastrointestinal tract. World J Gastroenterol 17 5231-5239, 2011.

15. Zhao JJ, Lin J, Lwin T, Yang H, Guo J, Kong W, Dessureault S, Moscinski LC, Rezania D, Dalton WS, et al: MicroRNA expression profile and identification of miR-29 as a prognostic marker and pathogenetic factor by targeting CDK6 in mantle cell lymphoma. Blood 115: 2630-2639, 2010.
16. Yamakuchi M,Ferlito $M$ and Lowenstein CJ: miR-34a repression of SIRT1 regulates apoptosis. Proc Natl Acad Sci USA 105: 13421-13426, 2008.

17. Tarasov V, Jung P, Verdoodt B, Lodygin D, Epanchintsev A, Menssen A, Meister G and Hermeking H: Differential regulation of microRNAs by $\mathrm{p} 53$ revealed by massively parallel sequencing: miR-34a is a p53 target that induces apoptosis and G1-arrest. Cell Cycle 6: 1586-1593, 2007.

18. Yan D, Zhou X, Chen X, Hu DN, Dong XD, Wang J, Lu F, Tu L and Qu J: MicroRNA-34a inhibits uveal melanoma cell proliferation and migration through downregulation of c-Met. Invest Ophthalmol Vis Sci 50: 1559-1565, 2009.

19. Gao C, Zhang Z, Liu W, Xiao S, Gu W and Lu H: Reduced microRNA-218 expression is associated with high nuclear factor kappa B activation in gastric cancer. Cancer 116: 41-49, 2010.

20. Iorio MV, Casalini P, Tagliabue E, Ménard S and Croce CM MicroRNA profiling as a tool to understand prognosis, therapy response and resistance in breast cancer. Eur J Cancer 44: 2753-2759, 2008

21. Chen X, Ba Y, Ma L, Cai X, Yin Y, Wang K, Guo J, Zhang Y, Chen J, Guo X, et al: Characterization of microRNAs in serum: A novel class of biomarkers for diagnosis of cancer and other diseases. Cell Res 18: 997-1006, 2008.

22. Weng OL, Pourmand N, Patterson BK: Patterns of known and novel small RNAS in human cervical cancer. Cancer Res 67: 6031-6043, 2007.

23. Raver-Shapira N, Marciano E, Meiri E, Spector Y, Rosenfeld N, Moskovits N, Bentwich Z and Oren M: Transcriptional activation of miR-34a contributes to p53-mediated apoptosis. Mol Cell 26: 731-743, 2007.

This work is licensed under a Creative Commons Attribution-NonCommercial-NoDerivatives 4.0 International (CC BY-NC-ND 4.0) License. 